\title{
Economic Consequences of Gender Equality in Europe
}

\author{
Biljana T. Baraković \\ University for Business Studies, Banjaluka, Bosnia and Herzegovina
}

\begin{abstract}
This paper shows influence of gender equality on economy where it analyzed how gender equality in Europe has affected on the development of the frozen food industry and services related to childcare. The development of these industries has given a positive impulse to the development of the whole economy. In this analysis, it is used multiple regressions as one of the most important statistical methods. In the first part of this paper, it shows the connection among the growth of female employment, growth in frozen food expenditure and growth of GDP in United Kingdom. In the second part of paper, it shows the relationship among the growth of labor force participation of women, growth of number of kindergarten and growth of GDP in Hungary. To proof these relationships, it used a multiple regression model. This statistical model was tested by using the $T$ schedule which showed that the model in both the analyses is correct. At the end of the paper, it presents that employment rate and GDP behaves in the same way in European Union. These analyses show that it is necessary to continue to strengthen gender equality if the policy makers want to achieve even greater economic growth. The issue of gender equality is a very important factor in creating employment policy, and statisticians should be more involved in process of employment policy and gender equality.
\end{abstract}

Keywords: gender equality, employment of women, multiple linear regression model, statistical tests, coefficient of determination

\section{Introduction}

Over the past 50 years, one of the largest changes to European economy has been the movement of women out of the home and into the workforce.

The major changes began to occur by passing principle of equal pay for equal work in Treaty of Rome in 1957 in Europe.

Gender equality is a fundamental right guaranteed by Article 23 of the Charter of Fundamental Rights of the European Union. In addition, Article 8 of the Treaty on the Functioning of the European Union states: "In all its activities, the Union shall aim to eliminate inequalities, and to promote equality, between men and women”. The commission has reaffirmed its commitment to gender equality by adopting the Women's Charter and adopting a Strategy for Equality between Women and Men (2010-2015). Achieving gender equality is also vital for the EU's growth, employment and social cohesion objectives. The Europe 2020 Strategy — the EU's key document for smart, sustainable and inclusive growth—has a headline target to raise the employment rate for women and men aged 20-64 to 75\% by 2020. (European Commission, 2011)

Biljana T. Baraković, Doctor of EconomicScience, Professor, Department of International Economy—Foreign Trade, University for Business Studies.

Correspondenceconcerningthisarticleshould be addressed to Biljana T. Baraković, Aleja Sv. Save 43, Banjaluka 78000, Bosnia and Herezegovina. E-mail: biljabarak@live.com. 
Equality is one of five values on which the European Union is founded. The Union is bound to strive for equality between women and men in all its activities. (European Commission, 2010)

Gender equality influences individual decisions such as decision about education, marriage, work, and parenthood.

Besides the impact on individual decisions, gender equality has a great impact on the economy.

In this paper, it provided empirical evidence of the influence of gender equality on the economy.

First, it will show the influence of gender equality on economy where it will proof that gender equality in Europe has affected on the development of frozen food industry and services related to childcare. The development of these industries has given a positive impulse to the development of the whole economy.

Then, it will show the influence of gender equality on economy where it will show connection between growth of women employment and growth of GDP in EU.

In these analyses, multiple regression model will be used.

\section{Influence of Gender Equality on Fast and Frozen Food Industry in Europe}

To understand how women have influenced the development of the industry of frozen food, it is necessary to go back to the 1950s and explain the main reasons for the emergence and development of frozen and fast food industry.

In the World War II, most women in America went to work in factories to replace men who were at the front. After war men returned and needed jobs. In that times government and media encouraged women to return home. But this effort was not as successful and was abandoned quickly. Women from lower economic ranks had to remain in the workforce because of economic necessity. Also in that time, there were important changes in socia-culture life, the rise of consumer culture and the spread of the television. Women wanted to have more and they found solutions in employment.

This way of life is transferred from America to Europe. Women wanted to work. In that situation food industries find its place on market.

In 1954, the editor of the Quick Frozen Food imagined a future world in which frozen food had emancipated women from the drudgery of their cooking routines, eliminated labor strife by keeping down the costs of living, and brought abundance to all American households. (Shane, 2002)

Beginning in the U.S. in the 1950s, the quick service restorans of McDonald's and Burger King expanded rapidly. Expansion through the 1960s occurred primarily in the U.S., but these restaurants began to open franchises around the world in the 1970s. Early expansion was concentrated in Canada, Western Europe, Japan, Hong Kong, Australia, and New Zealand. (Plummer \& Shiva, 2002)

Shortly saying, gender equality is influenced on the increasing number of working women (mothers) which do not have too much time for cooking or childcare. The market has recognized this problem and turned the development of industries like fast and frozen food and childcare. So, in past 60 years, there was increase of number of fast food restaurants, increase of number of baby sitters, kindergarten and big growth of food industries.

\section{Illustration of Impact of Women's Employment on Growth of Frozen Food Industries in Europe}

Illustration was done on example of United Kingdom. Reasons are simple: availability of statistical data. In 
other countries, it was very hard to find any statistical data about frozen food expenditure.

Table 1

Impact of Women's Employment on Growth of Frozen Food Industries in UK

\begin{tabular}{llll}
\hline Years & $\begin{array}{l}\text { UK GDP nominal chained GDP } \\
\text { (billion } £)\end{array}$ & $\begin{array}{l}\text { UK rate of unemployment } \\
\text { women }(\%)\end{array}$ & $\begin{array}{l}\text { UK frozen food expenditure 1967-1982 } \\
\text { Total at constant 1975 food prices (£ million) }\end{array}$ \\
\hline 1973 & 74.545 & 41.8 & 510 \\
1976 & 126.274 & 40.9 & 515 \\
1978 & 169.344 & 40.8 & 514 \\
1979 & 199.222 & 40.3 & 539 \\
1980 & 233.184 & 39.9 & 570 \\
\hline
\end{tabular}

Notes. Source for non-employment: Bell (2000); LFS Summary 1984-2002 (ONS website) (Rowthorn \& Webster, 2007). Source for UK frozen food expenditure: Birds eye (Grant, 1985). Source for GDP: retrieved from http://www.ukpublicspending.co.uk.

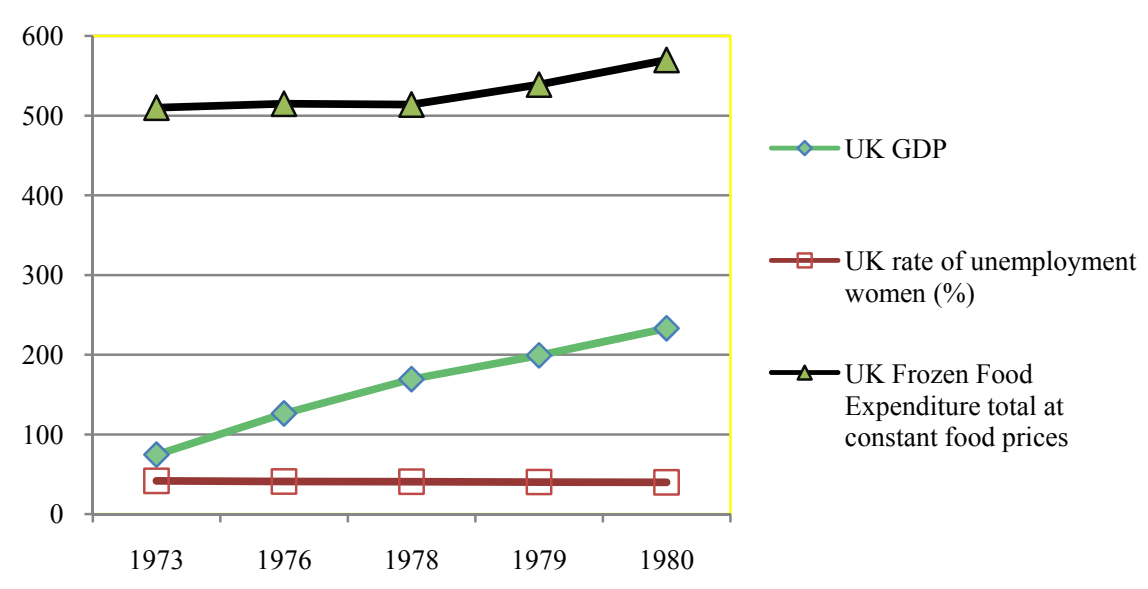

Figure 1. Impact of women's employment on growth of frozen food industries in UK.

From Table 1 and Figure 1, it can be seen that UK rate of unemployment women decreased from year to year, i.e., the employment rate increases. Here it can be seen the relationship between decrease of female unemployment, i.e., the growth of female employment and growth in UK frozen food expenditure and UK GDP.

To proof this relationship, multiple regression model is used, which is a very important tool for economists. Model specification includes selection of exogenous variables and functional forms of models.

Impact of women's employment on growth of frozen food industries is viewed from the standpoint of GDP in UK (dependent variable, $Y$ ), which is a function of UK rate of unemployment women (\%) (independent variable, $X_{1}$ ) and UK frozen food expenditure (independent variable, $X_{2}$ ).

The analysis of defined problem and selection of variables define the specification of the model in general form:

$$
\hat{Y}=b_{0}+b_{1} X_{1}+b_{2} X_{2}
$$

The model specification strategy was conditioned by the goals that are sought to be achieved. One goal was to predict the dependent or output variable, GDP. Another objective was to assess the marginal effect of each independent variable. Marginal change is more difficult to assess because the independent variables are associated not only with the dependent variable but also with each other.

If two or more independent variables change in mutual direct linear relationship, it is difficult to determine 
the individual effect of each independent variable on dependent variable. Now it will consider a multiple regression model in more detail.

The coefficients $b_{j}$ represent the evaluation of the unknown parameters, and they are derived based on the expressions below. The meaning of these coefficients is analogous to the meaning of the coefficients in the simple linear model. For example, coefficient $b_{0}$ indicates the expected values of dependant variable in the case where both independent values are equal zero, while coefficients $b_{1}$ and $b_{2}$ show average change of dependent variable (occurrence of $Y$ ) with the unit shift of one of the dependent variables, respectively.

Therefore, there is the next model:

$$
\begin{gathered}
b_{0}=\bar{y}-b_{1} \bar{X}_{1}-b_{2} \bar{X}_{2} \\
b_{1}=\frac{\sum d_{2}^{2} \sum d_{1} d_{y}-\sum d_{1} d_{2} \sum d_{2} d_{y}}{\sum d_{1}^{2} \sum d_{2}^{2}-\left(\sum d_{1} d_{2}\right)^{2}} \\
b_{2}=\frac{\sum d_{1}^{2} \sum d_{2} d_{y}-\sum d_{1} d_{2} \sum d_{1} d_{y}}{\sum d_{1}^{2} \sum d_{2}^{2}-\left(\sum d_{1} d_{2}\right)^{2}} \\
d_{1}=X_{1}-\bar{X}_{1} \\
d_{2}=X_{2}-\bar{X}_{2} \\
d_{y}=Y-\bar{Y}
\end{gathered}
$$

Solving this model, it is obtained:

$$
\begin{aligned}
& b_{0}=-113.623 \\
& b_{1}=12.625 \\
& b_{2}=-0.534
\end{aligned}
$$

So, the final model is:

$$
\hat{y}_{i}=-113.623+12.652 X_{1}-0.534 X_{2}
$$

Since coefficient $b_{0}$ indicates the expected value of the dependent variable in the case where both independent values are equal to zero, the value -113.623 indicates that the value of the dependent variable can be expected at this level with zero-level independent variables.

Value $b_{1}=12.652$ indicates the average change (increase) in GDP when UK's rate of unemployment women increases by the unit, and provides that UK's frozen food expenditure remains unchanged (this is a direct relation between the dependent and independent variables).

By analogy, $b_{2}=-0.534$ indicates the average change of GDP when UK's frozen food expenditure increases by the unit and UK's rate of unemployment women remains constant (this is the inverse relation between the dependent and independent variables because the regression coefficient has a negative sign).

Since the regression coefficients are absolute indicators, the phenomena included in the model are commonly reported in different measurement units, and it does not make sense to use them to compare their mutual influence of independent variables on the dependent variable. 
In the analysis, it was introduced the coefficient of multiple determinations to explain the variation percentage of GDP, explained by the mutual influence of independent variables included in the model:

$$
R_{Y / X_{1} X_{2}}^{2}=\frac{b_{1} \cdot \sum d_{1} d_{y}+b_{2} \cdot \sum d_{2} d_{y}}{\sum d_{y}^{2}}=0.8
$$

The coefficient of multiple determination indicates that $80 \%$ of the variance of GDP is explained by the mutual influence of UK rate of unemployment women (\%) and UK frozen food expenditure. What remains, i.e., $20 \%$, is the share of unexplained variability and shows the influence of those factors not included in the model.

To use a previously shown regression equation for assessing and predicting the value of GDP, first the significance of overall model must be tested. To test the validity of the model, the $T$ schedule is used. As realized value $t=13.44$ is greater than table value $t=2.92$ (with $5 \%$ risk), it can be concluded that the null hypothesis (that of UK rate of unemployment women and UK frozen food expenditure do not affect the GDP) should be rejected, i.e., that the model is adequate.

\section{Impact of Women's Employment of Growth of Service Connected to the Childcare}

Illustration was done on data taken from Hungary statistic. Once again it was very hard to find statistical data about number of kindergarten. There was only data in Hungary and that is the reason why this country is taken as an example.

Table 2

Connection Among GDP, Labor Force Participation, and Number of Kindergarten in Hungary

\begin{tabular}{llll}
\hline Years & GDP in billions & Labor force participation-women & Number of kindergarten \\
\hline 1960 & $3.1^{*}$ & 50 & 2,865 \\
1970 & 5.5425 & 58 & 3,456 \\
1980 & 22.1634 & 63 & 4,690 \\
1990 & 33.0561 & 62 & 4,718 \\
\hline
\end{tabular}

Notes. "Value of GDP in 1960 is an estimated trend made by author. Labor force participation was calculated as a proportion of the population aged 15-64. Value of GDP in 1960 is estimated. Soueces: Source for GDP: World Development indicators data base and CIA World Factbook; Source for Labor force participation: Reproduced from OECD (1991), Table A.2 (Punch \& Pearce, 2000). Source for number of kindergarten: OM Statisztika, (Pethő) (OECD Directorate for Education, 2004).

From Table 2, it can be seen that labor force participation of women in Hungary rise from decade to decade with the small decrease of one point in 1990. Here it can be seen the relationship between the growth of labor force participation of women in Hungary and growth of number of kindergarten and GDP in Hungary.

Now, GDP is a dependent variable $Y$ which is in function of labor force participation of women in Hungary (\%) (independent variable, $X_{1}$ ) and growth of number of kindergarten and GDP in Hungary (independent variable, $X_{2}$ ).

The analysis of defined problem and selection of variables define the specification of the model in general form:

$$
\begin{gathered}
\hat{Y}=b_{0}+b_{1} X_{1}+b_{2} X_{2} \\
b_{0}=\bar{y}-b_{1} \bar{X}_{1}-b_{2} \bar{X}_{2} \\
b_{1}=\frac{\sum d_{2}^{2} \sum d_{1} d_{y}-\sum d_{1} d_{2} \sum d_{2} d_{y}}{\sum d_{1}^{2} \sum d_{2}^{2}-\left(\sum d_{1} d_{2}\right)^{2}}
\end{gathered}
$$




$$
\begin{gathered}
b_{2}=\frac{\sum d_{1}^{2} \sum d_{2} d_{y}-\sum d_{1} d_{2} \sum d_{1} d_{y}}{\sum d_{1}^{2} \sum d_{2}^{2}-\left(\sum d_{1} d_{2}\right)^{2}} \\
d_{1}=X_{1}-\bar{X}_{1} \\
d_{2}=X_{2}-\bar{X}_{2} \\
d_{y}=Y-\bar{Y}
\end{gathered}
$$

Solving this model, it is obtained:

$$
\begin{aligned}
& b_{0}=-6.19168 \\
& b_{1}=-1.05161 \\
& b_{2}=0.02118
\end{aligned}
$$

So, the final model is:

$$
\hat{y}_{i}=-6.19168-1.05161 X_{1}+0.02118 X_{2}
$$

Since coefficient $b_{0}$ indicates the expected value of the dependent variable in the case where both independent values are equal to zero, the value -6.19168 indicates that the value of the dependent variable can be expected at this level with zero-level independent variables.

Value $b_{1}=-1.0516$ indicates the average change (increase) in GDP when labor force participation of women in Hungary increases by the unit, provided that number of kindergarten in Hungary remains unchanged.

By analogy, $b_{2}=0.02118$ indicates the average change of GDP when number of kindergarten in Hungary increases by the unit and labor force participation of women in Hungary remains constant.

To use a previously shown regression equation for assessing and predicting the value of GDP, first it must be tested the significance of overall model. To test the validity of the model, it is used the $T$ schedule. As realized value $t=100.79$ is greater than $t=6.3138$ ( with $5 \%$ risk), it can be concluded that the null hypothesis should be rejected.

\section{Connection Between Growth of Women Employment and Growth of GDP in European Union}

The analyses of impact of gender equality is finished with the presentation of connection between growth of women employment in EU and growth of GDP in EU. This connection can be seen from Table 3 and Figure 2.

Table 3

Connection Between Growth of Women Employment in EU and Growth of GDP in EU

\begin{tabular}{llllll}
\hline Years & 2000 & 2001 & 2002 & 2003 & 2004 \\
\hline \% change in real GDP & 3.9 & 2 & 1.3 & 1.4 & 2.4 \\
Rates of employment growth of women (\%) & 3.1 & 2.1 & 1.5 & 0.8 & 1.4 \\
\hline
\end{tabular}

Note. Source for \% change in real GDP: IMF, September 2006. Retrieved from http://www.imf.org. Source for rates of employment of growth of women: European Commission, Employment and Social Affairs DG, Indicators for monitoring the Employment Guidelines 2005 compendium, Update May 15, 2006; based on Eurostat, Quarterly LFS data.

Figure 2 shows the same behavior of GDP and employment of women - at a time when GDP falls, it can be seen falling of female employment, at time when GDP is growing, it can be seen growing of female employment.

This is another proof that shows that a government has to strengthen the role of women in economic life if they want to achieve GDP growth. 


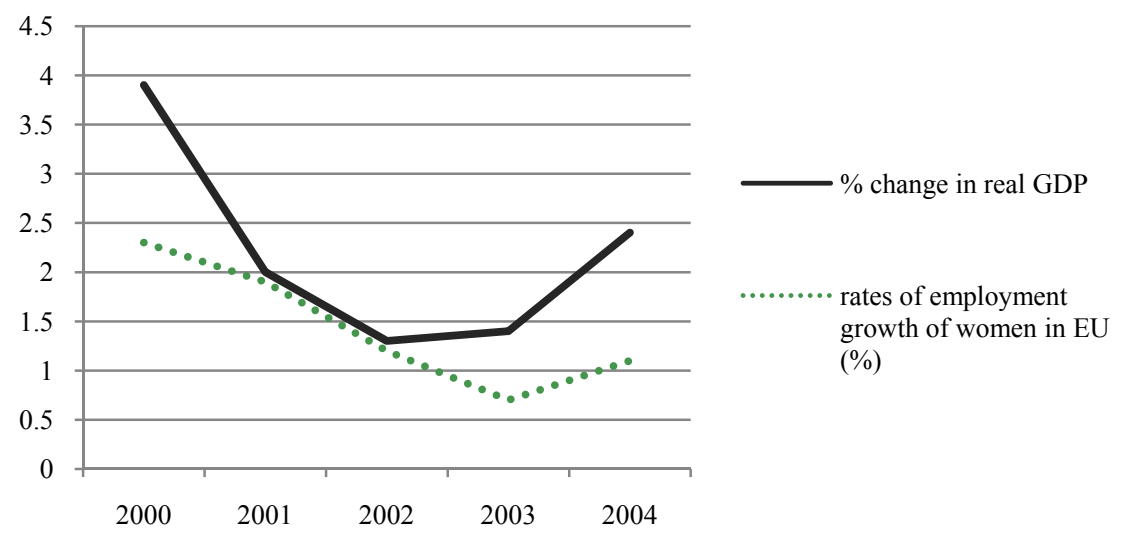

Figure 2. Connection between growth of women employment in EU and growth of GDP in EU.

\section{Conclusion}

The issue of gender equality has received growing attention among policy makers in European Union. The gender equality is an important factor in creating employment policy. In this paper, it is shown that greater involvement of women in economic life significantly affects the growth of GDP.

It is proved that gender equality and involvement of women in economic life made chain reaction on whole European and World's economy. With increase of women employment it is achieved growth of frozen food and childcare service industries that caused growth of employment which caused growth of GDP, growth of GDP caused bigger consumption and bigger consumption caused growth of production. This chain reaction led economy to the formation of a spiral of prosperity. All that is proved with a multiple regression model. These data are very important because they show that policy makers in European Union must take care to continue to strengthen gender equality if they want to achieve even greater economic growth.

The Europe 2020 strategy has vision for EU in next 10 years as a sustainable economy that delivers high employment, productivity and social cohesion. To achieve that it is needed to foster women's greater involvement in economy life.

Finally, it must not be forgotten that major reason for women's low employment rates is the challenge of family and private life. With better organization of children care it can be achieved greater women's employment. In doing this paper, it was found a number of difficulties in finding statistical data about kindergarten. It was very hard to find any data about kindergarten in Europe. So, it is necessary to introduce innovations in statistics. National statistical offices should be encouraged to make data about the number of kindergarten and other centers that are associated with the care and upbringing of children - because only by analyzing these and similar data, it can bring conclusions in determining why some areas have higher and some others lower employment of mothers. Shortly saying, official statisticians should be, together with policy makers, involved in process of employment policy and gender equality.

\section{References}

European Commission. (2010). Strategy for equality between women and men 2010-2015. Brussels.

European Commission. (2011). Report on progress on equality between women and men in 2010, The gender balance in business 
leadership. Publications Office of the European Union. Brussels.

Grant, M. R. (1985). Birds eye and the UK frozen food industry, case study. Retrieved from http://www.blackwellpublishing.com OECD Directorate for Education. (2004). Childhood education and care policy. Country note for Hungary. Retrived from htpp://www.oecd.org

Plummer, Ch., \& Shiva, M. (2002). French fries driving globalization of frozen potato industry, Economic Research Service/USDA, Agricultural Outlook.

Punch, A., \& Pearce, D. (2000). Europe's population and labor market beyond 2000 (Vol. 1): An assessment of trends and policy issues. Council of Europe, Strasbourg.

Rowthorn, R., \& Webster, D. (2007). Male worklessness and the rise of lone parenthood in BritainResearch. Working Paper No. 30. Oxford Centre for Population.

Shane, H. (2002). The economies and conveniences of modern-day living: Frozen food amd mass markting, 1945-1965. The Business History Review, 77. Retrieved from http://hbs.edu 